\title{
O futuro urbano nas economias emergentes
}

\author{
Ricardo Ojima*
}

\begin{abstract}
McGRANAHAN, Gordon; MARTINE, George (Ed.). Urban growth in emerging economies: lessons from the BRICS. New York: Routledge, 2014.
\end{abstract}

O livro organizado por Gordon McGranahan e George Martine sistematiza algumas análises resultantes de um esforço colaborativo entre o International Institute for Environment and Development (IIED) e o United Nation Population Fund (UNFPA), no sentido de compreender comparativamente as políticas, trajetórias e os impactos do processo de urbanização nas economias emergentes dos BRICS (Brasil, Rússia, Índia, China e África do Sul). Assim, o livro reúne sete capítulos, sendo que cinco retratam um panorama crítico de cada um dos BRICS e dois, um inicial e outro final, buscam, respectivamente, introduzir a problemática comum deles e apontar para cenários prospectivos.

Este conjunto de países se reuniu recentemente (julho de 2014) para discutir diretrizes conjuntas e a criação de um banco de desenvolvimento próprio que financiaria projetos de infraestrutura e desenvolvimento sustentável. Portanto, jogam um papel importante na economia mundial, além de características demográficas e sociais. No que se refere à infraestrutura, a problemática urbana é fundamental para que os investimentos sejam coerentes com o futuro desenvolvimento que se espera. Afinal, como enfatizado pelos organizadores do livro, elevados níveis do PIB estão geralmente associados a maiores níveis de urbanização.

Uma análise comparativa entre os países mostra que o processo de urbanização e suas características diferem muito, pois os contextos nos quais ocorrem são também muito diversos. O Brasil se destaca pela sua urbanização acelerada e precoce, enquanto a África do Sul é mais lenta. Índia e China apresentam elevados contingentes populacionais e os aspectos culturais tornam complexas as comparações em termos do que se pode esperar do planejamento urbano, por exemplo.

*Universidade Federal do Rio Grande do Norte - UFRN, Natal-RN, Brasil (ricardo.ojima@gmail.com). 
O próprio conceito aplicado por cada um dos países acerca do que se considera urbano não é único (como não o é entre os países em geral), o que torna ainda mais complexa a comparação entre os BRICS. Este aspecto, aliás, não é explorado pelo livro e confirma que se trata de um desafio preliminar de grande complexidade e fôlego. Mas, a despeito destas diferenças marcantes, se comparados a outros países e blocos econômicos, os BRICS serão os que mais contribuirão para o crescimento da população urbana do futuro. $\mathrm{E}$ tal argumento seria suficiente para justificar um desafio desta envergadura.

0 ritmo acelerado e o grande contingente populacional que passará a viver em cidades constituem um dos dilemas mais marcantes no que se refere ao planejamento do crescimento urbano. Como podemos avaliar a partir da experiência brasileira, a associação da transição demográfica com a transição urbana desenhou um cenário de crescimento populacional em áreas urbanas sem precedentes e sobre o qual havia pouco controle. Evidentemente, surge nesses cenários uma reação imediata de se tentar conter ou reverter o processo de urbanização, mas o que se percebe é que esses tipos de intervenção são quase sempre inócuos. A urbanização em si mesma não é o problema, pois viabilizaria melhor capacidade de oferta de serviços e otimizaria os investimentos em infraestrutura. Mas sem que haja a devida preparação e reflexão sobre os desafios que virão, pouco se pode fazer para que esse potencial positivo da urbanização seja atingido.

A migração rural-urbana é um aspecto que se destaca na compreensão do processo de urbanização em todos os BRICS e, como afirmam os autores do último capítulo, medidas antiurbanização diretas ou indiretas contribuem para a redução do potencial positivo que a urbanização poderia trazer. Ou seja, políticas que visem evitar os fluxos migratórios para as cidades tendem a dificultar a inclusão produtiva destes migrantes e naturalmente acabam produzindo um efeito inesperado contrário à intenção inicial. Para um estudioso dos problemas urbanos brasileiros, talvez essa afirmação não represente uma novidade, mas parece ser instigante pensar que outros países, com perspectivas de crescimento urbano parecidas com o Brasil, repetirão os equívocos de políticas públicas relacionadas ao mesmo processo.

A China propõe a construção de cidades rigorosamente planejadas, pois são construídas antes mesmo de ser dada a autorização para que as pessoas migrem. Conforme exposto no capítulo 3, diferentemente dos outros países, na China há uma regulação estatal da liberdade de migrar, o que contribui para que os empreendimentos econômicos possam tirar proveito das vantagens comparativas chinesas no que se refere à mão de obra a baixos custos. De certo, esse é um dos pontos mais importantes e explorados no capítulo, de forma a entender as particularidades chinesas. A migração rural-urbana, que antes era controlada, passou a ser incentivada de maneira a redistribuir a população de acordo com as diretrizes estatais.

0 caso russo, como detalhado no capítulo seguinte, evidencia as particularidades que o sistema político e a sua crise trouxeram para a constituição das cidades do país. Um dos destaques dos autores foram a carência de dados confiáveis e o controle da informação, até mesmo para a definição dos critérios usados para estimar a urbanização. 0 uso político do 
processo de urbanização deixou rastros que deverão se manter até hoje. Diferentemente do que a China vem propondo mais recentemente, a urbanização da região não buscou acomodar os aspectos econômicos, pois ocorreu ainda sob o regime soviético. Enfim, o planejamento urbano está, nos dias de hoje, descontextualizado do que se espera para o desenvolvimento do potencial urbano.

Por outro lado, as formas de intervenção sul-africanas talvez seja o que mais se aproxime do caso brasileiro e nota-se grande semelhança com algumas das políticas urbanas pouco exitosas que experimentamos por aqui. 0 crescimento de assentamentos urbanos sem infraestrutura adequada (como água, esgoto, etc.) e os mecanismos para reassentamentos e adequação destes locais parecem seguir os passos do que outrora ocorreu em cidades como São Paulo ou Rio de Janeiro. Assim, os capítulos 5 e 6 ilustram como a África do Sul e a Índia têm um passivo de infraestrutura a ser enfrentado. A exclusão e a segregação socioespacial, por diversas motivações distintas, se assemelham em suas consequências com o processo brasileiro.

O livro nos coloca diante de realidades diversas e contextos nos quais o crescimento urbano vem ocorrendo. Os capítulos dedicados a cada um dos países, embora não pretendam dar conta de todos os processos subjacentes, trazem pontos fundamentais para entender a complexidade do ritmo e desafio que o futuro aguarda. Para aquele leitor que busca compreender melhor os desafios da urbanização e suas interações com os aspectos sociais e demográficos, o livro é uma leitura importante não apenas porque tem a rubrica de instituições e autores que são referências no campo dos estudos urbanos, mas também por reunir e buscar a sistematização de uma discussão ainda carente de maior aprofundamento.

De modo geral, os BRICS estão em um contexto de transição demográfica já avançada no mundo. A urbanização em países que experimentaram há pouco a queda acelerada das taxas de fecundidade total coloca um contingente expressivo da sua população em idade adulta e uma redução do tamanho médio dos domicílios. Portanto, urbanizar-se logo após a transição demográfica terá seus custos, uma vez que existe uma demanda maior por domicílios. A (re)distribuição espacial da população constitui um fator importante na análise demográfica, pois é o componente que mais rapidamente responde a fatores sociais e econômicos. Nesse sentido, entender o processo de urbanização destes países não é apenas uma questão de planejamento urbano e regional, mas também evidencia o peso que os fatores demográficos podem ter nas decisões tomadas.

Assim, a obra nos coloca perguntas que precisam ser enfrentadas tanto para realizar as comparações que necessitam ser feitas entre os países deste bloco econômico, que aparentemente se tornará cada vez mais influente no campo geopolítico internacional, como para revisar alguns conceitos e preocupações que já havíamos deixado para trás enquanto país urbanizado que é o Brasil. Enfim, se os BRICS terão como foco o desenvolvimento sustentável e a melhoria da sua infraestrutura, entender melhor o papel e a articulação destes elementos com a urbanização é fundamental para a redução de problemas sociais. 


\section{Sobre o autor}

Ricardo Ojima é sociólogo e doutor em demografia pela Universidade Estadual de Campinas - Unicamp. Professor do Departamento de Demografia e Ciências Atuariais (DDCA), da Universidade Federal do Rio Grande do Norte - UFRN.

\section{Endereço para correspondência}

Universidade Federal do Rio Grande do Norte - UFRN

Centro de Ciências Exatas e da Terra - CCET, Departamento de Demografia e Ciências

Atuariais - DDCA

Avenida Salgado Filho, s/n, Lagoa Nova

59078-900 - Natal-RN, Brasil

Recebida para publicação em 17/09/2014

Recebida versão final e aceita para publicação em 22/05/2015 